ARTICLE

\title{
https://doi.org/10.1038/s41467-020-20643-w OPEN
}

\section{Nonpolarizing oxygen-redox capacity without O-O dimerization in $\mathrm{Na}_{2} \mathrm{Mn}_{3} \mathrm{O}_{7}$}

\author{
Akihisa Tsuchimoto1,5, Xiang-Mei Shi (10 1,5, Kosuke Kawai ${ }^{1}$, Benoit Mortemard de Boisse1, Jun Kikkawa², \\ Daisuke Asakura (i) ${ }^{3}$, Masashi Okubo ${ }^{1,4}$ \& Atsuo Yamada (1) ${ }^{1,4 凶}$
}

Reversibility of an electrode reaction is important for energy-efficient rechargeable batteries with a long battery life. Additional oxygen-redox reactions have become an intensive area of research to achieve a larger specific capacity of the positive electrode materials. However, most oxygen-redox electrodes exhibit a large voltage hysteresis $>0.5 \mathrm{~V}$ upon charge/discharge, and hence possess unacceptably poor energy efficiency. The hysteresis is thought to originate from the formation of peroxide-like $\mathrm{O}_{2}{ }^{2-}$ dimers during the oxygen-redox reaction. Therefore, avoiding $\mathrm{O}-\mathrm{O}$ dimer formation is an essential challenge to overcome. Here, we focus on $\mathrm{Na}_{2-x} \mathrm{Mn}_{3} \mathrm{O}_{7}$, which we recently identified to exhibit a large reversible oxygen-redox capacity with an extremely small polarization of $0.04 \mathrm{~V}$. Using spectroscopic and magnetic measurements, the existence of stable $\mathrm{O}^{-\bullet}$ was identified in $\mathrm{Na}_{2-x} \mathrm{Mn}_{3} \mathrm{O}_{7}$. Computations reveal that $\mathrm{O}^{-} \bullet$ is thermodynamically favorable over the peroxide-like $\mathrm{O}_{2}{ }^{2-}$ dimer as a result of hole stabilization through a $(\sigma+\pi)$ multiorbital $\mathrm{Mn}-\mathrm{O}$ bond.

\footnotetext{
${ }^{1}$ Department of Chemical System Engineering, School of Engineering, The University of Tokyo, Hongo 7-3-1, Bunkyo-ku Tokyo 113-8656, Japan. ${ }^{2}$ National Institute for Materials Science (NIMS), Tsukuba Ibaraki 305-0044, Japan. ${ }^{3}$ National Institute of Advanced Industrial Science and Technology (AIST), Umezono 1-1-1, Tsukuba Ibaraki 305-8568, Japan. ${ }^{4}$ Elements Strategy Initiative for Catalysts \& Batteries (ESICB), Kyoto University, Nishikyo-ku Kyoto 6158245, Japan. ${ }^{5}$ These authors contributed equally: Akihisa Tsuchimoto, Xiang-Mei Shi. ${ }^{\bowtie}$ email: yamada@chemsys.t.u-tokyo.ac.jp
} 
ithium-ion batteries are presently the de facto standard power sources for portable electronic devices and electric vehicles due to their high energy density and efficiency relying on intercalation chemistry, whereby a host electrode material reversibly accommodates lithium ions without a large structural change $\mathrm{e}^{1-3}$. As the reaction Gibbs energy for the oxidation of an electrode material $\left(\left|\Delta_{\mathrm{r}} G^{\text {ox }}\right|\right)$ is almost the same as that for the reduction $\left(\left|\Delta_{\mathrm{r}} G^{\text {red }}\right|\right)$, the charge/discharge processes of an intercalation electrode usually proceed with minimal energy loss. For any electrochemical energy storage devices, the use of reversible redox chemistry $\left(\left|\Delta_{\mathrm{r}} G^{\mathrm{OX}}\right| \approx\left|\Delta_{\mathrm{r}} G^{\text {red }}\right|\right)$ is a primary requisite to maximize their energy efficiency.

Lithium-rich transition metal oxides $\left(\mathrm{Li}_{1+x} \mathrm{M}_{1-x} \mathrm{O}_{2}, \mathrm{M}=\right.$ transition metal) are promising large-capacity positive electrode materials for lithium-ion batteries, as they exhibit accumulative redox reactions of $\mathrm{M}$ and $\mathrm{O}^{4-6}$. However, the voltage profile of $\mathrm{Li}_{1+x} \mathrm{M}_{1-x} \mathrm{O}_{2}$ typically includes a large hysteresis during initial and subsequent charge/discharge cycles, in part due to structural changes such as cation migration and surface cation densification $^{7-9}$. Although the oxygen-redox-active sodium counterpart $\mathrm{Na}_{x} \mathrm{M}_{y} \mathrm{O}_{2}$ can partly suppress cation migration due to the larger ionic size difference between $\mathrm{Na}$ and $\mathrm{M}$, a large voltage hysteresis is still observed in many cases ${ }^{10-18}$. As energy efficiency is crucial for energy storage devices, the voltage hysteresis of oxygen-redox electrodes should be addressed for their practical application.

Although the mechanism of the oxygen-redox reaction is still under debate, it is generally accepted that nonbonding oxygen $2 p$ states free from $\mathrm{M}-\mathrm{O} \sigma$ hybridization are localized just below the Fermi level to contribute to oxygen oxidation ${ }^{19-24}$; however, the chemical state of oxidized oxygen remains controversial. Considering the large voltage hysteresis $\left(\left|\Delta_{\mathrm{r}} G^{\text {ox }}\right| \neq\left|\Delta_{\mathrm{r}} G^{\text {red }}\right|\right)$, oxidized oxide ions $\left(\mathrm{O}^{-\bullet}\right)$ are believed to form stable peroxide-like $\mathrm{O}_{2}{ }^{2-}$ dimers upon charging. Upon subsequent discharging, the $\mathrm{O}_{2}^{2-}$ dimer may be initially reduced to $\mathrm{O}_{2}{ }^{4-}$, and then decomposed to $\mathrm{O}^{2-}$ (Fig. 1a) ${ }^{16,25-29}$. Besides such thermodynamic hysteresis, there is an overlapping kinetic hysteresis arising from concentration overpotential when transition-metal migration and/or surface cation densification occur in parallel, making elucidation of the overall mechanisms difficult ${ }^{7-9}$.

In striking contrast to the large voltage hysteresis $(>0.5 \mathrm{~V})$ observed for most oxygen-redox electrodes, $\mathrm{Na}_{2-x} \mathrm{Mn}_{3} \mathrm{O}_{7}$ was very recently discovered to exhibit a highly reversible oxygen-redox capacity with negligible voltage hysteresis $(<0.04 \mathrm{~V})^{30-33}$. Hence, $\mathrm{Na}_{2} \mathrm{Mn}_{3} \mathrm{O}_{7}$ can serve as an excellent counterpart (Fig. 1b, $\left.\left|\Delta_{\mathrm{r}} G^{\mathrm{ox}}\right| \approx\left|\Delta_{\mathrm{r}} G^{\text {red }}\right|\right)$ for insights into the origin of the typically large voltage hysteresis observed upon oxygen redox. $\mathrm{Na}_{2} \mathrm{Mn}_{3} \mathrm{O}_{7}$ possesses a layered structure comprising alternatively stacked $\mathrm{Na}$ and Mn slabs (Fig. 2a inset) with characteristic Mn vacancies ( $\square$ ) in $\sqrt{7} \times \sqrt{7}$ in-plane ordering ${ }^{34}$. Density functional theory (DFT) calculations suggested that a localized oxygen $2 p$ orbital along the Na-O- $\square$ axis contributes to the oxygen-redox capacity 31 . While the nonpolarizing oxygen-redox capacity strongly implicates charge compensation from the reversible redox couple of $\mathrm{O}^{2-} / \mathrm{O}^{-}$(Fig. 1b) without any contribution from $\mathrm{O}_{2}{ }^{2-}$, no experimental evidence for the stable existence of $\mathrm{O}^{-} \cdot$ has been identified for any oxygen-redox electrodes. Also important is unveiling how $\mathrm{O}^{-} \cdot$ is stabilized in $\mathrm{Na}_{2-x} \mathrm{Mn}_{3} \mathrm{O}_{7}$.

Herein, evidences confirming the existence of $\mathrm{O}^{-\bullet}$ as the dominant state in the highly reversible oxygen redox of $\mathrm{Na}_{2-x} \mathrm{Mn}_{3} \mathrm{O}_{7}$ are provided. After magnetic susceptibility measurements to confirm the major contribution of $\mathrm{O}^{-\cdot}$, the thermodynamically favorable presence of $\mathrm{O}^{-} \cdot$ over peroxide-like $\mathrm{O}_{2}^{2-}$ in $\mathrm{Na}_{2-x} \mathrm{Mn}_{3} \mathrm{O}_{7}$ is substantiated via DFT calculations, and finally, the hole stabilization mechanism of $\mathrm{O}^{-} \cdot$ is examined.

\section{Results}

Nonpolarizing oxygen redox in $\mathrm{Na}_{2} \mathrm{Mn}_{3} \mathrm{O}_{7} \cdot \mathrm{Na}_{2} \mathrm{Mn}_{3} \mathrm{O}_{7}$ was synthesized from a solid-state reaction following a reported procedure $^{30,31}$. The powder X-ray diffraction pattern for the resulting compound (Supplementary Fig. 1) is indexed to triclinic

\section{a Conventional $\mathrm{O}$ redox}

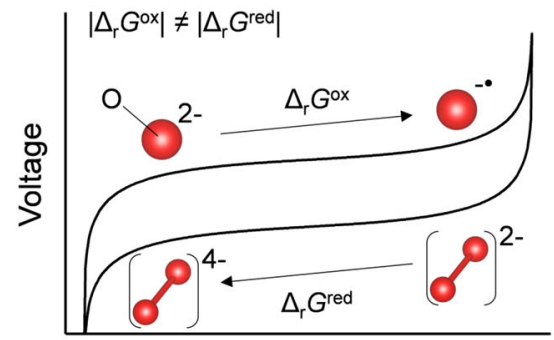

Capacity

\section{b Ideal O redox}

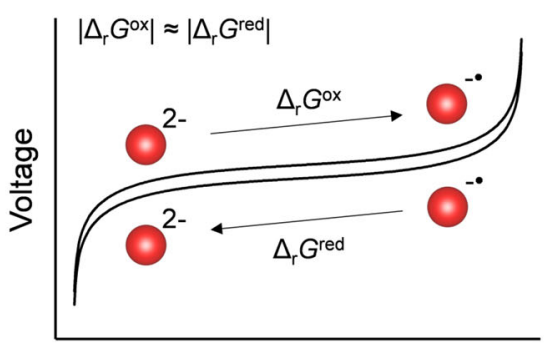

Capacity

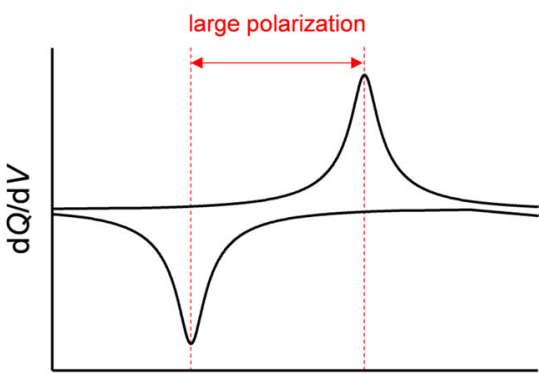

Voltage

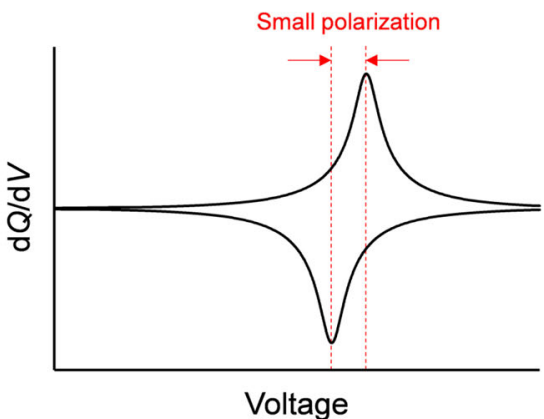

Fig. 1 Polarizing and nonpolarizing oxygen-redox positive electrodes. Schematic illustration of charge/discharge curves and dQ/dV plots ( $Q$ : specific capacity, $V$ : reaction voltage) for a conventional oxygen redox with large polarization $\left(\mathrm{O}^{2-} / \mathrm{O}_{2}{ }^{2-}\right)$, and $\mathbf{b}$ ideal oxygen redox with small polarization $\left(\mathrm{O}^{2-} / \mathrm{O}^{-\bullet}\right)$. The red sphere denotes oxygen atom. 
a

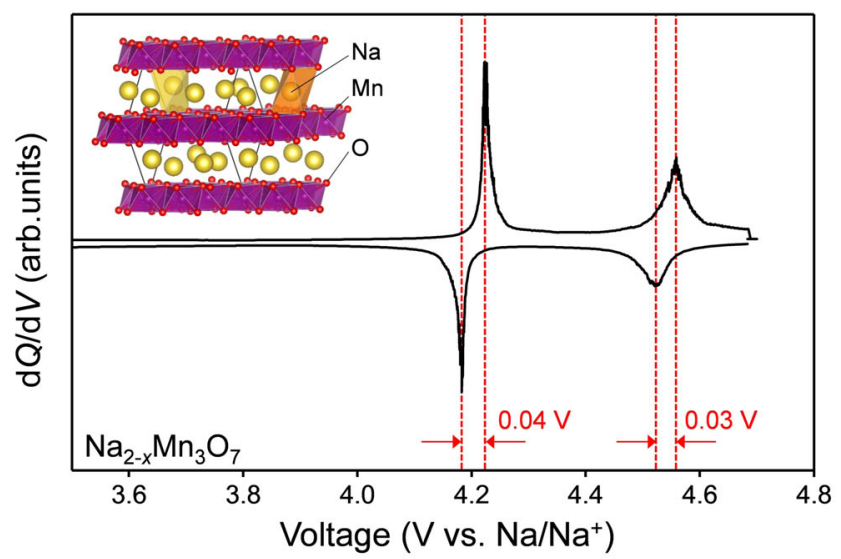

b

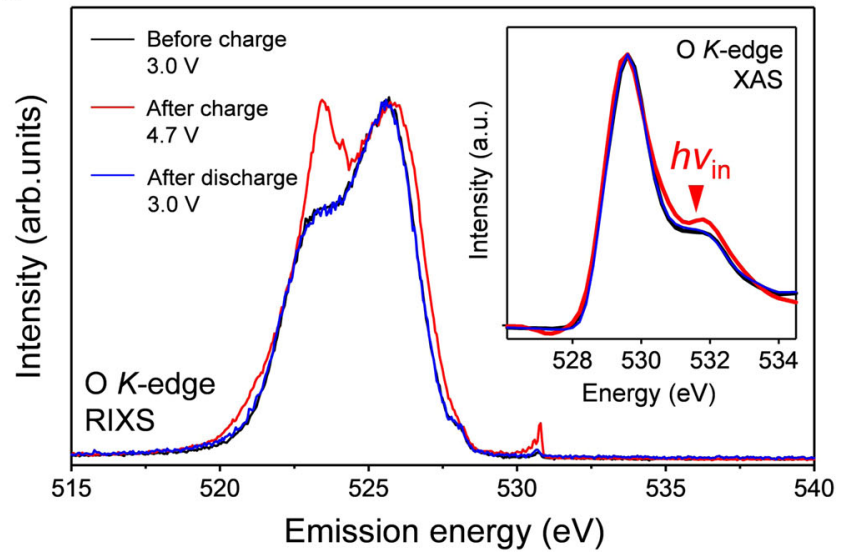

Fig. 2 Non-polarizing oxygen-redox positive electrode $\mathrm{Na}_{2} \mathrm{Mn}_{3} \mathrm{O}_{7}$. a dQ/ $d V$ plot (Q: specific capacity, $V$ : reaction voltage) of $\mathrm{Na}_{2-x} \mathrm{Mn}_{3} \mathrm{O}_{7}$ at $\mathrm{C} / 20$ during the second charge/discharge cycle between 3.0-4.7 $\mathrm{V}$ vs. $\mathrm{Na} / \mathrm{Na}^{+}$. Inset shows the crystal structure of $\mathrm{Na}_{2} \mathrm{Mn}_{3} \mathrm{O}_{7}$ (yellow sphere: sodium, purple sphere: manganese, red sphere: oxygen). b O K-edge resonant inelastic $\mathrm{X}$-ray scattering (RIXS) spectra for $\mathrm{Na}_{2-x} \mathrm{Mn}_{3} \mathrm{O}_{7}$ before the second charge (3.0 V, black line), after the second charge $(4.7 \mathrm{~V}$, red line), and after the second discharge ( $3.0 \mathrm{~V}$, blue line) with excitation energy of 531.5 $\mathrm{eV}$. Inset shows corresponding $\mathrm{O} \mathrm{K}$-edge $\mathrm{X}$-ray absorption spectra (XAS).

$P \overline{1}$, confirming the successful synthesis of $\mathrm{Na}_{2} \mathrm{Mn}_{3} \mathrm{O}_{7}$. The selected-area electron diffraction (SAED) pattern (Supplementary Fig. 2a) reveals the ordered arrangement of $\mathrm{Mn}$ atoms and vacancies in the Mn slab $(\sqrt{7} \times \sqrt{7}$ superlattice). The charge/ discharge curves at a rate of $\mathrm{C} / 20$ show a reversible oxygen-redox capacity of approximately $70 \mathrm{mAh} / \mathrm{g}$ (Supplementary Fig. 3), which is consistent with a previous report ${ }^{31}$. Fig. 2a shows the $\mathrm{d} Q / \mathrm{d} V$ plot for $\mathrm{Na}_{2-x} \mathrm{Mn}_{3} \mathrm{O}_{7}$ between 3.0 and $4.7 \mathrm{~V}$ vs. $\mathrm{Na} / \mathrm{Na}^{+}$ during the second charge/discharge cycle. As the nominal valence state of $\mathrm{Mn}$ in $\mathrm{Na}_{2} \mathrm{Mn}_{3} \mathrm{O}_{7}$ is tetravalent (maximum valence of octahedral Mn), the redox center in $\mathrm{Na}_{2-x} \mathrm{Mn}_{3} \mathrm{O}_{7}$ is a priori attributable to oxygen; the $\mathrm{Mn} L$-edge $\mathrm{X}$-ray absorption spectra in our previous work confirmed the negligible contribution of $\mathrm{Mn}$ redox to the capacity ${ }^{31}$. Importantly, the $d Q / d V$ peaks of the charge/discharge processes have an extremely small voltage hysteresis of merely $0.03-0.04 \mathrm{~V}$, implicating the reversible redox reaction of oxygen $\left(\mathrm{O}^{2-} / \mathrm{O}^{-} \cdot\right)$ (Fig. 1b) without peroxidelike $\mathrm{O}_{2}^{2-}$ formation (Fig. 1a).

$\mathrm{O} K$-edge X-ray absorption spectra (Fig. $2 \mathrm{~b}$ inset) show the emergence of a new absorption peak at $531.5 \mathrm{eV}$ after the charge process, which corresponds to the excitation of an $\mathrm{O} 1 \mathrm{~s}$ core electron to an $\mathrm{O} 2 \mathrm{p}$ hole, as commonly observed for other oxygen-redox electrodes ${ }^{35-38}$. To monitor the detailed valence partial density of states (pDOS) of oxygen, resonant inelastic Xray scattering (RIXS) spectra were measured using an incident photon of $531.5 \mathrm{eV}$. The emergence of a new emission peak at $523 \mathrm{eV}$ in the RIXS spectrum for charged $\mathrm{Na}_{2-x} \mathrm{Mn}_{3} \mathrm{O}_{7}$ is typical for charged oxygen-redox electrodes $s^{5,24,28,39,40}$. Although $\mathrm{O}^{-} \cdot$ formation is implicated by the small voltage hysteresis in the charge/discharge processes (Fig. 2a), the new inelastic scattering can be explained by either (1) energy loss from a $\pi(\mathrm{Mn}-\mathrm{O}) \rightarrow \pi^{*}$ $(\mathrm{Mn}-\mathrm{O})$ transition $\left(\mathrm{O}^{-\bullet}\right.$ formation), or (2) energy loss from a $\sigma$ $(\mathrm{O}-\mathrm{O}) \rightarrow \sigma^{*}(\mathrm{O}-\mathrm{O})$ transition (peroxide-like $\mathrm{O}_{2}{ }^{2-}$ formation $)^{40}$. While observation of the new RIXS peak at $523 \mathrm{eV}$ confirms the occurrence of the oxygen-redox reaction itself in $\mathrm{Na}_{2-x} \mathrm{Mn}_{3} \mathrm{O}_{7}$, but this evidence alone does not definitely identify the reaction mechanism, or the chemical state of the oxidized oxygen species.

Magnetic elucidation of $\mathrm{O}^{-}$. To identify the oxidized species, we measured the magnetic susceptibility $(\chi)$ of $\mathrm{Na}_{2-x} \mathrm{Mn}_{3} \mathrm{O}_{7}$ with respect to its sensitivity to local coordination structures and electronic configurations. Figure $3 \mathrm{a}$ shows the temperature dependence of $\chi^{-1}$ during the second charge/discharge cycle. The $\chi^{-1}$ vs. $T$ plot follows the Curie-Weiss law $\left(\chi=\frac{C}{T-\Theta}, C=\right.$ Curie constant, $\Theta=$ Weiss temperature) at high temperature ( $>200 \mathrm{~K}$ ), providing the spin-state information of $\mathrm{Mn}$ and $\mathrm{O}$ in $\mathrm{Na}_{2-x} \mathrm{Mn}_{3} \mathrm{O}_{7}$. Because the ordered arrangement of $\mathrm{Mn}$ atoms and vacancies in the Mn slab is maintained after the charge process, as confirmed from the SAED pattern (Supplementary Fig. 2b), in-plane and out-of-plane Mn migrations do not occur in $\mathrm{Na}_{2-x} \mathrm{Mn}_{3} \mathrm{O}_{7}$. Therefore, the magnetic property changes are ascribed solely to the spin-state changes of $\mathrm{Mn}$ and $\mathrm{O}$. Figure $3 \mathrm{~b}$ shows the values of $C$ and $\Theta$ as a function of $x$ in $\mathrm{Na}_{2-x} \mathrm{Mn}_{3} \mathrm{O}_{7}$. Before the charge process, the value of $C\left(5.77 \mathrm{~cm}^{3} \mathrm{~K} \mathrm{~mol}^{-1}\right)$ agrees with the calculated value $\left(5.63 \mathrm{~cm}^{3} \mathrm{~K} \mathrm{~mol}^{-1}\right.$ for $\left.g=2.0\right)$ for three $\mathrm{Mn}^{4+}(S=3 / 2)$ in $\mathrm{Na}_{2} \mathrm{Mn}_{3} \mathrm{O}_{7}$. The negative $\Theta$ of $-192 \mathrm{~K}$ indicates an in-plane antiferromagnetic interaction between $\mathrm{Mn}^{4+}$ cations ${ }^{41}$, which contradicts the prediction of ferromagnetic superexchange from the Goodenough-Kanamori rule $^{42}$. This magnetic behavior is ascribed to the deviation of $\mathrm{Mn}$ $\mathrm{O}-\mathrm{Mn}$ bond angles from $90^{\circ}$, which most likely induces the antiferromagnetic superexchange; an antiferromagnetic $d$ - $d$ direct exchange interaction may also exist, as reported for $\mathrm{Li}_{2} \mathrm{MnO}_{3}{ }^{43}$.

The value of $C$ monotonically decreases to $4.22 \mathrm{~cm}^{3} \mathrm{~K} \mathrm{~mol}^{-1}$ upon charge, which is close to the calculated value $\left(4.75 \mathrm{~cm}^{3} \mathrm{~K}\right.$ mol $^{-1}$ for $\left.g=2.0\right)$ under a simple assumption that $\mathrm{Mn}^{4+} \mathrm{O}^{-} \cdot$ behaves as $S=S_{\mathrm{Mn}}+S_{\mathrm{O}}=1$ (Zhang-Rice triplet) ${ }^{44-46}$. Note that the Zhang-Rice triplet in $\mathrm{Na}_{2-x} \mathrm{Mn}_{3} \mathrm{O}_{7}$ arises from $\pi$-type direct exchange while the Zhang-Rice singlet originally proposed for superconducting cupper oxides is generated via $\sigma$-type direct exchange ${ }^{44}$. Diamagnetic peroxide-like $\mathrm{O}_{2}{ }^{2-}$ formation, which should yield a constant $C$, is clearly ruled out by the observed decrease in $C$, as speculated from the very small hysteresis in the $\mathrm{d} Q / \mathrm{d} V$ plot. The increase in $\Theta$ upon charge suggests the increment of ferromagnetic superexchange interaction between Mn spins through bridging $\mathrm{O}^{-\bullet}$ over the effects of antiferromagnetic superexchange or $d$ - $d$ direct exchange. After discharge, both $C$ and $\Theta$ return to their initial values, supporting the reversibility of the charge/discharge processes without structural or electronic degradations. Overall, the magnetic measurements support the reversible oxygen-redox reaction of $\mathrm{O}^{2-} / \mathrm{O}^{-}$(Fig. 1b) in $\mathrm{Na}_{2-x} \mathrm{Mn}_{3} \mathrm{O}_{7}$.

$\mathbf{O}^{-\bullet}$ vs. $\mathbf{O}_{2}^{2-}$. Why does $\mathrm{Na}_{2-x} \mathrm{Mn}_{3} \mathrm{O}_{7}$ specifically exhibit the reversible oxygen-redox reaction of $\mathrm{O}^{2-} / \mathrm{O}^{-} \cdot$ ? To answer this question, we compared the thermodynamic stability of $\mathrm{O}^{-}$and 

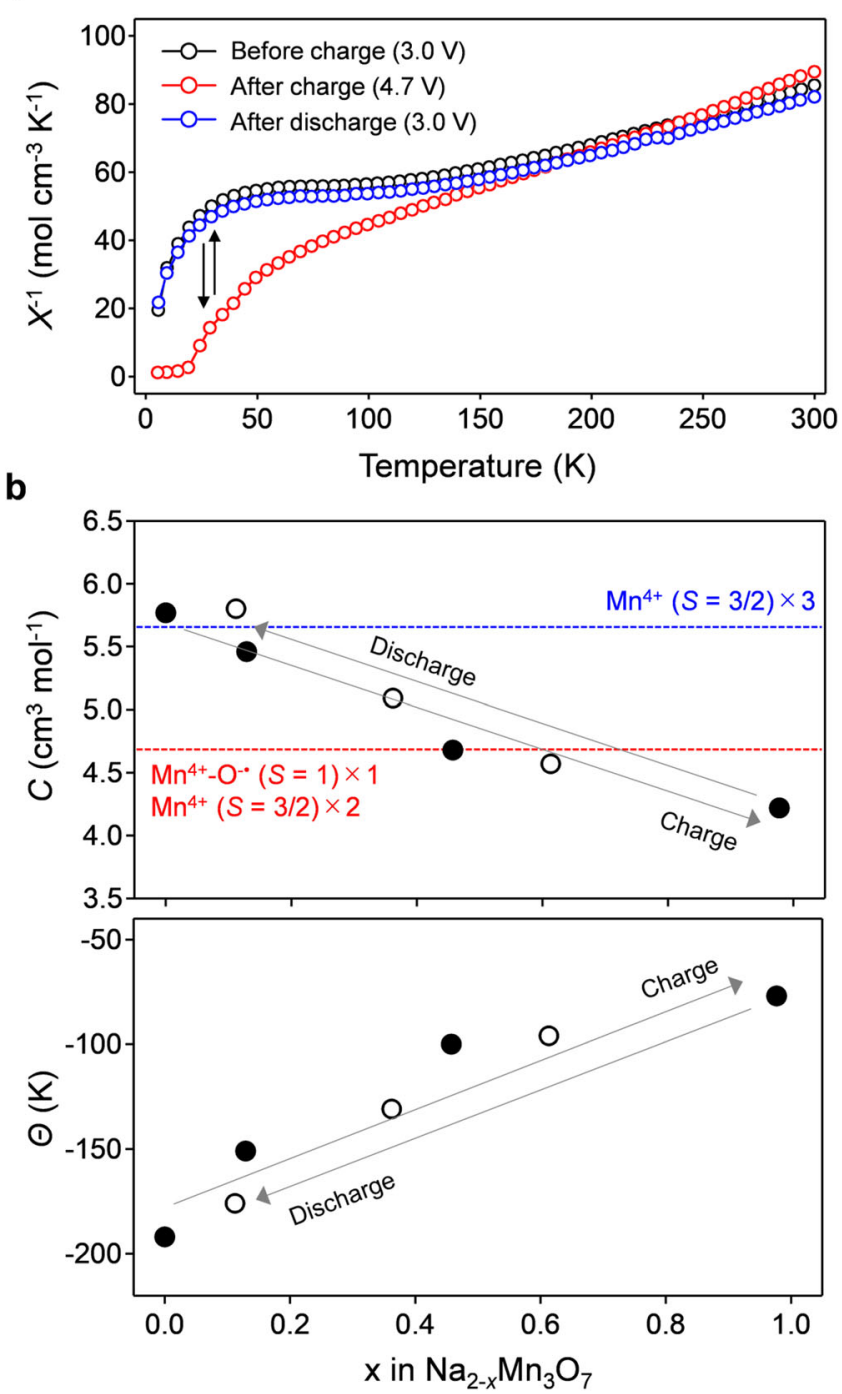

Fig. 3 Magnetic elucidation of the existence of $\mathrm{O}^{-}$in $\mathrm{Na}_{2-x} \mathrm{Mn}_{3} \mathrm{O}_{7}$. a The inverse of a magnetic susceptibility $(\chi)$ as a function of temperature, and $\mathbf{b}$ Curie constant $(C)$ and Weiss temperature $(\Theta)$ for $\mathrm{Na}_{2-x} \mathrm{Mn}_{3} \mathrm{O}_{7}$ during the second cycle. Filled and empty circles correspond to data points for the charge and discharge processes, respectively.

peroxide-like $\mathrm{O}_{2}{ }^{2-}$ in $\mathrm{Na}_{2-x} \mathrm{Mn}_{3} \mathrm{O}_{7}$ using DFT calculations. Figure $4 \mathrm{a}$ shows the calculated magnetic moments of $\mathrm{Mn}$ and $\mathrm{O}$ in optimized structures without peroxide-like $\mathrm{O}_{2}{ }^{2-}$ (Supplementary Fig. 4a). For the experimentally accessible desodiation range $(0 \leq$ $x \leq 1$ in $\left.\mathrm{Na}_{2-x} \mathrm{Mn}_{3} \mathrm{O}_{7}\right)$, a magnetic moment gradually emerges on the $\mathrm{O}$ atoms upon desodiation, which indicates $\mathrm{O}^{-}$formation. The slight decrease in the average magnetic moment of $\mathrm{Mn}$ is explained by the initiation of metal-to-ligand charge transfer ( $\pi$ back-donation) from the formation of a ligand hole $\left(\mathrm{O}^{-\bullet}\right)^{40}$. The calculated voltage profile under the $\mathrm{O}^{-}$- formation model (Fig. 5 and Supplementary Fig. 5) accurately reproduces the experimentally observed voltage plateaus $(4.30$ and $4.53 \mathrm{~V})$, further supporting $\mathrm{O}^{-\bullet}$ formation in $\mathrm{Na}_{2-x} \mathrm{Mn}_{3} \mathrm{O}_{7}$.

The formation energy of peroxide-like $\mathrm{O}_{2}{ }^{2-}$ in $\mathrm{Na}_{2-x} \mathrm{Mn}_{3} \mathrm{O}_{7}$ was calculated for various $\mathrm{O}-\mathrm{O}$ pairs, where calculated $\mathrm{O}-\mathrm{O}$ bond lengths for the lowest energy structures are in the peroxide $\mathrm{O}_{2}{ }^{2-}$ range of 1.46-1.47 $\AA$ (Supplementary Fig. $4 \mathrm{~b})^{47}$. The average magnetic moment of the O-O dimers is small $\left(-0.094(6) \mu_{\mathrm{B}}\right)$, also suggesting the formation of peroxide-like $\mathrm{O}_{2}{ }^{2-}$ rather than superoxide-like $\mathrm{O}_{2}{ }^{-}$when $\mathrm{O}-\mathrm{O}$ dimerization occurs. The a

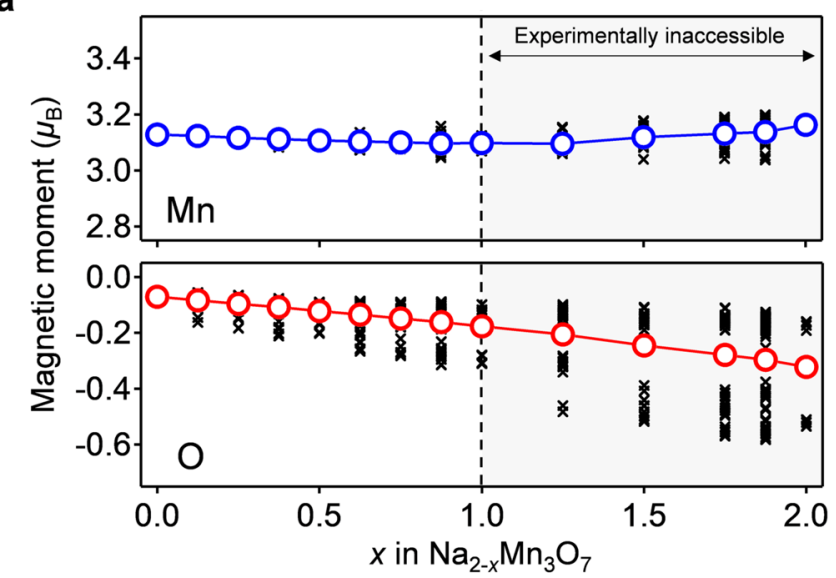

b

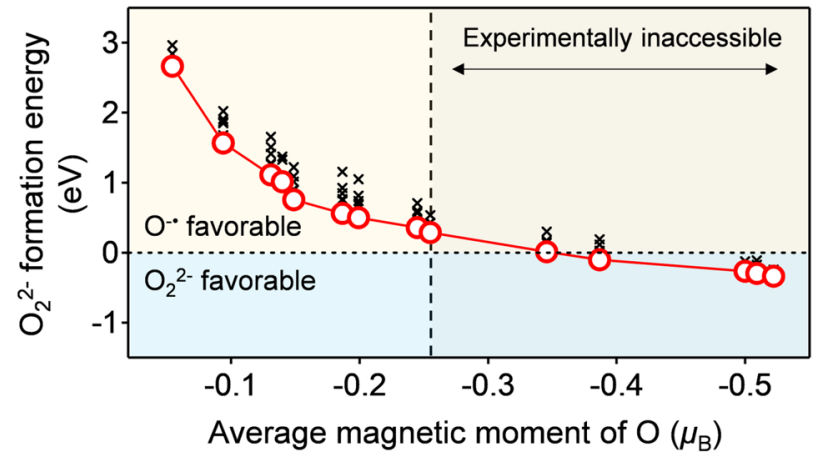

Fig. 4 Theoretical derivation of stable existence of $\mathrm{O}^{-\bullet}$ in $\mathrm{Na}_{2-x} \mathrm{Mn}_{3} \mathrm{O}_{7}$. a Calculated magnetic moments of $\mathrm{Mn}$ and $\mathrm{O}$ as a function of $x$ in $\mathrm{Na}_{2-x} \mathrm{Mn}_{3} \mathrm{O}_{7}$, and $\mathbf{b}$ calculated formation energy of peroxide-like $\mathrm{O}_{2}{ }^{2-}$ as a function of the average magnetic moment (i.e., degree of oxidation) of $\mathrm{O}$ in $\mathrm{Na}_{2-x} \mathrm{Mn}_{3} \mathrm{O}_{7}$. For the plots of the magnetic moments, black crosses are a magnetic moment of each atom, while blue and red circles are average magnetic moments. For the plot of the formation energy, black crosses represent the formation energy of various $\mathrm{O}-\mathrm{O}$ pairs, while red circles represent the lowest value at each desodiated state. Gray shaded area is experimentally inaccessible due to too high desodiation potential (see Supplementary Fig. S5).

formation energy of $\mathrm{O}_{2}{ }^{2-}$ (Fig. 4b) was calculated as the difference between the total energies of $\mathrm{Na}_{2-x} \mathrm{Mn}_{3} \mathrm{O}_{7}$ with $\mathrm{O}^{-}$and with $\mathrm{O}_{2}{ }^{2-}$ as a function of the average magnetic moment of $\mathrm{O}$ (i.e., the degree of $\mathrm{O}$ oxidation). During the experimentally accessible charge process $\left(0 \leq x \leq 1\right.$ in $\left.\mathrm{Na}_{2-x} \mathrm{Mn}_{3} \mathrm{O}_{7}\right)$, the formation energy of $\mathrm{O}_{2}^{2-}$ is positive relative to that of $\mathrm{O}^{-}$, indicating that $\mathrm{Na}_{2-x} \mathrm{Mn}_{3} \mathrm{O}_{7}$ with $\mathrm{O}^{-} \cdot$ is thermodynamically favorable compared to $\mathrm{Na}_{2-x} \mathrm{Mn}_{3} \mathrm{O}_{7}$ with $\mathrm{O}_{2}{ }^{2-}$. Presumably, a hole on $\mathrm{O}^{-\bullet}$ in $\mathrm{Na}_{2-x} \mathrm{Mn}_{3} \mathrm{O}_{7}$ is stabilized through a $(\sigma+\pi)$ multiorbital Mn-O bond ${ }^{40}$, as demonstrated using a crystal orbital overlap populations (COOP) analysis in our previous works ${ }^{31}$. Note that, in parallel with a localized feature, the oxygen hole has an itinerant feature through the $(\sigma+\pi)$ multiorbital interaction. Indeed, the experimentally observed value of $C$ for $\mathrm{Na}_{1} \mathrm{Mn}_{3} \mathrm{O}_{7}$ $\left(4.22 \mathrm{~cm}^{3} \mathrm{~K} \mathrm{~mol}^{-1}\right)$ is slightly lower than that calculated for a localized model $\left(4.75 \mathrm{~cm}^{3} \mathrm{~K} \mathrm{~mol}^{-1}\right)$ (Fig. 3b).

Figure $4 \mathrm{a}$ also indicates that further oxygen oxidation leads to negative $\mathrm{O}_{2}{ }^{2-}$ formation energy $\left(\mathrm{O}_{2}{ }^{2-}\right.$ favorable): the oxygen oxidation lowers the energy level of $\mathrm{O} 2 p$ well below that of $\mathrm{Mn}$ $t_{2 \mathrm{~g}}$, which renders $\mathrm{Mn}-\mathrm{O}$ interaction weak ${ }^{48}$. In the balance of competing stabilization mechanisms via $(\sigma+\pi)$ multiorbital Mn$\mathrm{O}$ bond versus peroxide $\mathrm{O}-\mathrm{O}$ bond, the adequate oxygen-redox capacity (approximately $70 \mathrm{mAh} / \mathrm{g}$, Supplementary Fig. 3) keeps 

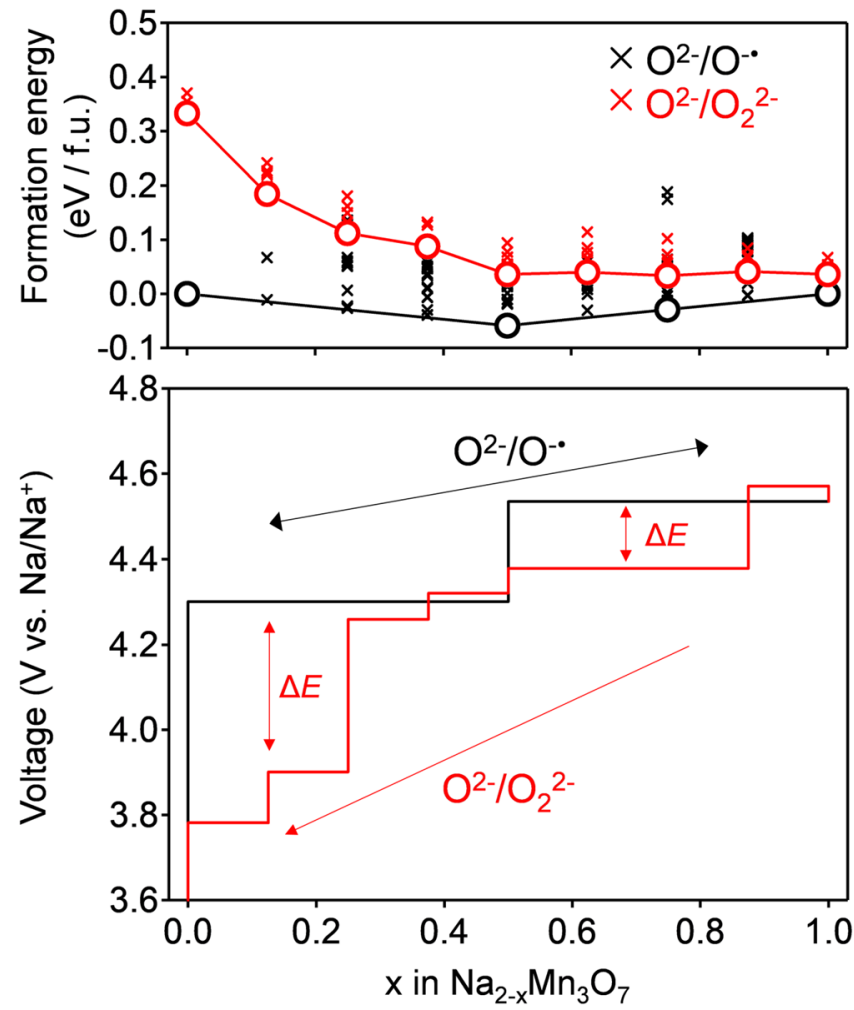

Fig. 5 Predicted voltage hysteresis of $\mathrm{Na}_{2-x} \mathrm{Mn}_{3} \mathrm{O}_{7}$ with hypothetical peroxide-like $\mathbf{O}_{2}{ }^{2-}$ dimers. DFT calculated convex hull and voltage profile of $\mathrm{Na}_{2-x} \mathrm{Mn}_{3} \mathrm{O}_{7}$ with $\mathrm{O}^{-\bullet}$ and with $\mathrm{O}_{2}{ }^{2-}$. The formation energies of both pristine structures and peroxide phases were calculated relative to pristine $\mathrm{Na}_{2} \mathrm{Mn}_{3} \mathrm{O}_{7}$ and $\mathrm{NaMn}_{3} \mathrm{O}_{7}$ phases. Black and red crosses in the convex hull are formation energies of $\mathrm{Na}_{2-x} \mathrm{Mn}_{3} \mathrm{O}_{7}$ with $\mathrm{O}^{-\bullet}$ and with $\mathrm{O}_{2}{ }^{2-}$,

respectively. Black and red circles are the lowest states at various desodiated states. The black solid line of the voltage profile represents the charge/discharge curves without $\mathrm{O}_{2}{ }^{2-}$ formation, while the red solid line represents the discharge curve for hypothetical $\mathrm{Na}_{2-x} \mathrm{Mn}_{3} \mathrm{O}_{7}$ with $\mathrm{O}_{2}{ }^{2-}$.

the $(\sigma+\pi)$ multiorbital stabilization dominant, making $\mathrm{O}^{-\bullet}$ stable in $\mathrm{Na}_{2-x} \mathrm{Mn}_{3} \mathrm{O}_{7}$. It should also be emphasized that the calculated voltage profile for the sodiation of $\mathrm{Na}_{2-x} \mathrm{Mn}_{3} \mathrm{O}_{7}$ with $\mathrm{O}_{2}{ }^{2-}$ shows a voltage hysteresis of $0.3-0.5 \mathrm{~V}$ relative to the charge process of $\mathrm{Na}_{2-x} \mathrm{Mn}_{3} \mathrm{O}_{7}$ with $\mathrm{O}^{-} \cdot$ (Fig. 5), which clearly contradicts the experimental observations. $\mathrm{O}_{2}{ }^{2-}$ formation is therefore inhibited in $\mathrm{Na}_{2-x} \mathrm{Mn}_{3} \mathrm{O}_{7}$, leading to an $\mathrm{O}^{2-} / \mathrm{O}^{-\bullet}$ based reversible and nonpolarizing oxygen-redox capacity. Excessive oxidation of oxygen (e.g., $x \geq 1$ in $\mathrm{Na}_{2-x} \mathrm{Mn}_{3} \mathrm{O}_{7}$ ), which drives $\mathrm{O}^{-}$to dimerization, is an absolute taboo for a nonpolarizing oxygenredox capacity 48,49 . Based on this criterion, the oxygen-redox reaction should be employed as an auxiliary charge-compensation mechanism under a prudent control rather than as a main charge-compensation mechanism.

\section{Discussion}

As recently demonstrated using O2-type layered oxides ${ }^{23,50}$, the suppression of cation migration is essential to mitigate the degradation of oxygen-redox cathodes. However, although cation migration should accelerate $\mathrm{O}-\mathrm{O}$ dimer formation ${ }^{16,20,51}$, the suppression of cation migration alone is not enough to explain nonpolarizing oxygen-redox reaction. For example, P2- and P3$\mathrm{Na}_{2 / 3} \mathrm{Mg}_{x} \mathrm{Mn}_{1-x} \mathrm{O}_{2}$ deliver large extra oxygen-redox capacities greater than $100 \mathrm{mAh} / \mathrm{g}$ with large polarization, where $\mathrm{O}-\mathrm{O}$ dimers could be formed without cation migration ${ }^{15,52}$. This scenario, O-O dimerization without cation migration, is indeed predicted by the DFT calculations (Fig. 4). Correlation between cation migration and $\mathrm{O}-\mathrm{O}$ dimerization involving thermodynamic and kinetic issues, and its influence on the voltage hysteresis is debatable, calling for further studies.

In summary, multiple experimental and computational pieces of evidence were identified to confirm the $\mathrm{O}^{2-} / \mathrm{O}^{-} \cdot$ based reversible and nonpolarizing oxygen-redox reaction in $\mathrm{Na}_{2-x} \mathrm{Mn}_{3} \mathrm{O}_{7}$. The competitive $\mathrm{O}_{2}{ }^{2-}$ formation is energetically unfavorable when low-concentration $\mathrm{O}^{-\bullet}$ (i.e., $\left.<\mathrm{Na}_{1} \mathrm{Mn}_{3}\left(\mathrm{O}^{-\bullet}\right)_{1} \mathrm{O}_{6}\right)$ is highly stabilized by a $(\sigma+\pi)$ multiorbital $\mathrm{Mn}-\mathrm{O}$ bond. To the best of our knowledge, this is the first experimental confirmation of the existence of $\mathrm{O}^{-} \cdot$ in an oxygen-redox electrode. Considering the importance of energy efficiency, the exclusive use of $\mathrm{O}^{2-} / \mathrm{O}^{-} \cdot$ as a redox couple is a primary requisite to utilize oxygen-redox electrodes in practical battery applications, identifying a crucial criterion for the development of efficient nonpolarizing oxygenredox electrodes.

\section{Methods}

Electrochemistry. $\mathrm{Na}_{2} \mathrm{Mn}_{3} \mathrm{O}_{7}$ was synthesized by sintering the stoichiometric mixture of $\mathrm{NaNO}_{3}$ and $\mathrm{MnCO}_{3}$ at $600{ }^{\circ} \mathrm{C}$ under $\mathrm{O}_{2}$ flow for $4 \mathrm{~h}^{30,31}$. Electrochemical measurements were conducted using CR2032-type coin cells. Positive electrodes consisted of $80 \mathrm{wt} \% \mathrm{Na}_{2} \mathrm{Mn}_{3} \mathrm{O}_{7}, 10 \mathrm{wt} \%$ acetylene black, and $10 \mathrm{wt} \%$ polyvinylidene difluoride (PVDF), which were coated on $\mathrm{Al}$ foil using $\mathrm{N}$ methylpyrrolidone (NMP) as the solvent. Sodium was used as the negative electrode, with $1.0 \mathrm{M} \mathrm{NaPF}_{6}$ in ethylene carbonate (EC)/diethyl carbonate (DEC) (1:1 $\mathrm{v} / \mathrm{v} \%)$ as the electrolyte. The cells were cycled at a charge/discharge rate of C/20.

X-ray absorption/emission. Ex situ X-ray absorption spectroscopy (XAS) and resonant inelastic X-ray scattering (RIXS) measurements were performed on samples without exposure to air at BL07LSU of SPring-8. A bulk-sensitive partial fluorescence yield (PFY) mode was employed for O K-edge XAS. Extended X-ray absorption fine structure was conducted at the BL-9C Beamline of the Photon Factroy, KEK, Japan. SAED patterns were recorded using an electron microscope (Titan Cubed, FEI Co.) operated at $80 \mathrm{kV}$ after transferring the samples without exposure to air.

Calculations. All structures were calculated using DFT, as implemented in the Vienna Ab Initio Simulation Package (VASP) ${ }^{53,54}$. The projector-augmented wave pseudopotential and a plane-wave basis set with an energy cut-off of $520 \mathrm{eV}$ were used $^{55}$. The generalized gradient approximation (GGA) with the Perdew-BurkeErnzerhof functional describes the exchange-correlation energy ${ }^{56,57}$. To remove the self-interaction error, the Hubbard $U$ correction was applied to the $d$ electrons of Mn atoms $\left(U_{\text {eff }}=3.9 \mathrm{eV}\right)^{58,59}$. The $k$-point was sampled on a $3 \times 3 \times 5$ grid for all calculations. The Grimme scheme (DFT-D3) was applied to include van der Waals corrections $^{60}$. Crystal structures were visualized with VESTA software ${ }^{61}$.

We constructed a $2 \times 2 \times 1$ supercell $\left(\mathrm{Na}_{16-i} \mathrm{Mn}_{24} \mathrm{O}_{56}\right)$ to calculate a series of charged-structures of $\mathrm{Na}_{2-x} \mathrm{Mn}_{3} \mathrm{O}_{7}(0<x \leq 2)$. All possible cation orderings $\left(\mathrm{Na}^{+}\right)$ were searched in the Supercell program, with the exclusion of symmetrical duplicates ${ }^{62}$. Considering the large number of configurations in the initial search (e.g., 1670 for $\mathrm{Na}_{8} \mathrm{Mn}_{24} \mathrm{O}_{56}$ ), we conducted a multi-step calculation of total energies to determine the stable cation ordering for each structure. First, we simply calculated the total energies without geometry optimization and selected the 100 lowest-energy configurations for each charged-structure. Second, we optimized both the lattice and atomic positions of the selected configurations under a force convergence of $0.03 \mathrm{eV}^{-1}$, where the energy cut-off and number of $k$ points were reduced to $400 \mathrm{eV}$ and $1 \times 1 \times 3$, respectively. At this point, we screened out the 20 lowest-energy configurations for each structure. Finally, we reconducted the geometry optimization with a more reliable energy cut-off $(520 \mathrm{eV})$ and $k$-point mesh $(3 \times 3 \times 5)$ under a force convergence of $0.01 \mathrm{eV}^{-1}$, identifying all the lowest-energy structures in the charge process.

The convex hull was constructed to identify the stable phases among the determined structures, with the formation energies (at $0 \mathrm{~K}$ ) calculated as:

$$
E_{\mathrm{f}}\left(\mathrm{Na}_{2-x} \mathrm{Mn}_{3} \mathrm{O}_{7}\right)=E\left(\mathrm{Na}_{2-x} \mathrm{Mn}_{3} \mathrm{O}_{7}\right)-\frac{2-x}{2} E\left(\mathrm{Na}_{2} \mathrm{Mn}_{3} \mathrm{O}_{7}\right)-\frac{x}{2} E\left(\mathrm{Mn}_{3} \mathrm{O}_{7}\right)
$$

where $E\left(\mathrm{Na}_{2-x} \mathrm{Mn}_{3} \mathrm{O}_{7}\right)$ is the total energy of $\mathrm{Na}_{2-x} \mathrm{Mn}_{3} \mathrm{O}_{7}$ at $0 \leq x \leq 2$. The voltage profile was then evaluated ${ }^{63}$, with the average voltage of the reaction between two adjacent stable phases calculated as:

$$
U\left(x_{1}, x_{2}\right)=-\frac{E\left(\mathrm{Na}_{2-x_{1}} \mathrm{Mn}_{3} \mathrm{O}_{7}\right)-E\left(\mathrm{Na}_{2-x_{2}} \mathrm{Mn}_{3} \mathrm{O}_{7}\right)-\left(x_{2}-x_{1}\right) \mu_{\mathrm{Na}}}{\left(x_{2}-x_{1}\right) \mathrm{F}}
$$

where $\mu_{\mathrm{Na}}$ is the chemical potential of Na metal and $F$ is the Faraday constant. The representative structures are shown in Supplementary Fig. $4 \mathrm{a}$.

The formation of peroxide-like $\mathrm{O}_{2}{ }^{2-}$ in $\mathrm{Na}_{2-x} \mathrm{Mn}_{3} \mathrm{O}_{7}$ was calculated by creating a short $\mathrm{O}-\mathrm{O}$ bond in $\mathrm{Na}_{16-i} \mathrm{Mn}_{24} \mathrm{O}_{56}$, as shown in Supplementary Figure 4b. After the atomic positions were fully relaxed, no other significant structural change was 
found except for the $\mathrm{O}-\mathrm{O}$ dimer. The formation energy of $\mathrm{O}_{2}{ }^{2-}$ was calculated by:

$$
E_{\mathrm{f}}\left(\mathrm{O}_{2}^{2-}, x\right)=E\left(\mathrm{O}_{2}^{2-}, x\right)-E\left(\mathrm{Na}_{2-x} \mathrm{Mn}_{3} \mathrm{O}_{7}\right)
$$

where $E\left(\mathrm{O}_{2}^{2-}, x\right)$ is the total energy of $\mathrm{Na}_{2-x} \mathrm{Mn}_{3} \mathrm{O}_{7}$ with peroxide-like $\mathrm{O}_{2}^{2-}$. The voltage profile of the discharge process for $\mathrm{Na}_{2-x} \mathrm{Mn}_{3} \mathrm{O}_{7}$ with peroxide-like $\mathrm{O}_{2}{ }^{2-}$ was calculated based on the same cation orderings considered in the charge process.

\section{Data availability}

The whole datasets are available from the corresponding author on reasonable request.

Received: 26 August 2020; Accepted: 14 December 2020;

Published online: 27 January 2021

\section{References}

1. Goodenough, J. B. How we made the Li-ion rechargeable battery. Nat. Electron. 1, 204 (2018).

2. Whittingham, M. S. Ultimate limits to intercalation reactions for lithium batteries. Chem. Rev. 114, 11414-11443 (2014).

3. Yoshino, A. The birth of the lithium-ion battery. Angew. Chem. Int. Ed. $\mathbf{5 1}$ 5798-5800 (2012).

4. Assat, G. \& Tarascon, J.-M. Fundamental understanding and practical challenges of anionic redox activity in Li-ion batteries. Nat. Energy 3, 373-386 (2018).

5. Gent, W. E., Abate, I. I., Yang, W., Nazar, L. F. \& Chueh, W. C. Design rules for high-valent redox in intercalation electrodes. Joule 4, 1369-1397 (2020).

6. Yabuuchi, N. Material design concept of lithium-excess electrode materials with rocksalt-related structures for rechargeable non-aqueous batteries. Chem. Rec. 19, 690-707 (2019).

7. Tran, N. et al. Mechanisms associated with the "plateau" observed at high voltage for the overlithiated $\mathrm{Li}_{1.12}\left(\mathrm{Ni}_{0.425} \mathrm{Mn}_{0.425} \mathrm{Co}_{0.15}\right)_{0.88} \mathrm{O}_{2}$ system. Chem. Mater. 20, 4815-4825 (2008).

8. Xu, B., Fell, C. R., Chi, M. F. \& Meng, Y. S. Identifying surface structural changes in layered Li-excess nickel manganese oxides in high voltage lithium ion batteries: a joint experimental and theoretical study. Energy Environ. Sci. 4 2223-2233 (2011).

9. $\mathrm{Ku}, \mathrm{K}$. et al. A new lithium diffusion model in layered oxides based on asymmetric but reversible transition metal migration. Energy Environ. Sci. 13, 1269-1278 (2020).

10. Rozier, P. et al. Anionic redox chemistry in Na-rich $\mathrm{Na}_{2} \mathrm{Ru}_{1-\mathrm{y}} \mathrm{Sn}_{\mathrm{y}} \mathrm{O}_{3}$ positive electrode material for $\mathrm{Na}$-ion batteries. Electrochem. Commun. 53, 29-32 (2015).

11. Mortemard de Boisse, B. et al. Intermediate honeycomb ordering to trigger oxygen redox chemistry in layered battery electrode. Nat. Commun. 7, 11397 (2016).

12. Mortemard de Boisse, B. et al. Coulombic self-ordering upon charging a largecapacity layered cathode material for rechargeable batteries. Nat. Commun. 10, 2185 (2019).

13. Sato, K. et al. Na-excess cation-disordered rocksalt oxide: $\mathrm{Na}_{1.3} \mathrm{Nb}_{0.3} \mathrm{Mn}_{0.4} \mathrm{O}_{2}$. Chem. Mater. 29, 5043-5047 (2017).

14. Kobayashi, T. et al. Nanosize cation-disordered rocksalt oxides: $\mathrm{Na}_{2} \mathrm{TiO}_{3}$ $\mathrm{NaMnO}_{2}$ binary system. Small 16, 1902462 (2020).

15. Maitra, U. et al. Oxygen redox chemistry without excess alkali-metal ions in $\mathrm{Na}_{2 / 3}\left[\mathrm{Mg}_{0.28} \mathrm{Mn}_{0.72}\right] \mathrm{O}_{2}$. Nat. Chem. 10, 288-295 (2018).

16. House, R. A. et al. Superstructure control of first-cycle voltage hysteresis in oxygen-redox cathodes. Nature 577, 502-508 (2020).

17. Yabuuchi, N. et al. New O2/P2-type Li-excess layered manganese oxides as promising multi-functional electrode materials for rechargeable $\mathrm{Li} / \mathrm{Na}$ batteries. Adv. Energy Mater. 4, 1301453 (2014).

18. Rong, X. et al. Structure-induced reversible anionic redox activity in $\mathrm{Na}$ layered oxide cathode. Joule 2, 125-140 (2018).

19. Luo, K. et al. Charge-compensation in 3d-transition-metal-oxide intercalation cathodes through the generation of localized electron holes on oxygen. Nat. Chem. 8, 684-691 (2016).

20. Seo, D. H. et al. The structural and chemical origin of the oxygen redox activity in layered and cation-disordered Li-excess cathode materials. Nat. Chem. 8, 692-697 (2016).

21. Perez, A. J. et al. Approaching the limits of cationic and anionic electrochemical activity with the Li-rich layered rocksalt $\mathrm{Li}_{3} \mathrm{IrO}_{4}$. Nat. Energy 2, 954-962 (2017).

22. Zhan, C. et al. Enabling the high capacity of lithium-rich anti-fluorite lithium iron oxide by simultaneous anionic and cationic redox. Nat. Energy 2, 963-971 (2017).
23. Eum, D. et al. Voltage decay and redox asymmetry mitigation by reversible cation migration in lithium-rich layered oxide electrodes. Nat. Mater. 19, 419-427 (2020)

24. Okubo, M. \& Yamada, A. Molecular principles of oxygen-redox battery electrodes. ACS Appl. Mater. Interfaces 9, 36463-36472 (2017).

25. Sathiya, M. et al. Reversible anionic redox chemistry in high-capacity layeredoxide electrodes. Nat. Mater. 12, 827-835 (2013).

26. McCalla, E. et al. Visualization of O-O peroxo-like dimers in high-capacity layered oxides for Li-ion batteries. Science 350, 1516-1521 (2015).

27. Gent, W. E. et al. Coupling between oxygen redox and cation migration explains unusual electrochemistry in lithium-rich layered oxides. Nat. Commun. 8, 2091 (2017).

28. Hong, J. et al. Metal-oxygen decoordination stabilizes anion redox in Li-rich oxides. Nat. Mater. 18, 256-265 (2019).

29. Assat, G., Glazier, S. L., Delacourt, C. \& Tarascon, J.-M. Probing the thermal effects of voltage hysteresis in anionic redox-based lithium-rich cathodes using isothermal calorimetry. Nat. Energy 4, 647-656 (2019).

30. Adamczyk, E. \& Pralong, V. $\mathrm{Na}_{2} \mathrm{Mn}_{3} \mathrm{O}_{7}$ : a suitable electrode material for $\mathrm{Na}$ ion batteries? Chem. Mater. 29, 4645-4648 (2017).

31. Mortemard de Boisse, B. et al. Highly reversible oxygen-redox chemistry at 4.1 $\mathrm{V}$ in $\mathrm{Na}_{4 / 7-\mathrm{x}}\left[\square_{1 / 7} \mathrm{Mn}_{6 / 7}\right] \mathrm{O}_{2}$ ( $\square$ : Mn vacancy). Adv. Energy Mater. 8, 1800409 (2018).

32. Song, B. H. et al. Understanding the low-voltage hysteresis of anionic redox in $\mathrm{Na}_{2} \mathrm{Mn}_{3} \mathrm{O}_{7}$. Chem. Mater. 31, 3756-3765 (2019)

33. Wang, Q., Yang, W., Kang, F. \& Li, B. $\mathrm{Na}_{2} \mathrm{Mn}^{3+}{ }_{0.3} \mathrm{Mn}^{4+}{ }_{2.7} \mathrm{O}_{6.85}$ : a cathode with simultaneous cationic and anionic redox in Na-ion battery. Energy Storage Mater. 14, 361-366 (2018).

34. Chang, F. M. \& Jansen, M. Darstellung und kristallstruktur von $\mathrm{Na}_{2} \mathrm{Mn}_{3} \mathrm{O}_{7} . Z$. Anorg. Allg. Chem. 531, 177-182 (1985).

35. Oishi, M. et al. Charge compensation mechanisms in $\mathrm{Li}_{1.16} \mathrm{Ni}_{0.15} \mathrm{Co}_{0.19} \mathrm{Mn}_{0.50} \mathrm{O}_{2}$ positive electrode material for Li-ion batteries analyzed by a combination of hard and soft X-ray absorption near edge structure. J. Power Sources 222, 45-51 (2013).

36. Yabuuchi, N. et al. High-capacity electrode materials for rechargeable lithium batteries: $\mathrm{Li}_{3} \mathrm{NbO}_{4}$-based system with cation-disordered rocksalt structure. Proc. Natl Acad. Sci. USA 112, 7650-7655 (2015).

37. Yabuuchi, N. et al. Origin of stabilization and destabilization in solid-state redox reaction of oxide ions for lithium-ion batteries. Nat. Commun. 7, 13814 (2016).

38. Yamamoto, K. et al. Charge compensation mechanism of lithium-excess metal oxides with different covalent and ionic characters revealed by operando soft and hard X-ray absorption spectroscopy. Chem. Mater. 32, 139-147 (2020).

39. $\mathrm{Xu}$, J. et al. Elucidating anionic oxygen activity in lithium-rich layered oxides. Nat. Commun. 9, 947 (2018).

40. Sudayama, T. et al. Multiorbital bond formation for stable oxygen-redox reaction in battery electrodes. Energy Environ. Sci. 13, 1492-1500 (2020).

41. Venkatesh, C. et al. Magnetic properties of the one-dimensional $\mathrm{S}=3 / 2$ Heisenberg antiferromagnetic spin-chain compound $\mathrm{Na}_{2} \mathrm{Mn}_{3} \mathrm{O}_{7}$. Phys. Rev. $B$ 101, 184429 (2020)

42. Kanamori, J. Superexchange interaction and symmetry properties of electron orbitals. J. Phys. Chem. Solids 10, 87-98 (1959).

43. Lee, S. et al. Antiferromagnetic ordering in $\mathrm{Li}_{2} \mathrm{MnO}_{3}$ single crystals with a two-dimensional honeycomb lattice. J. Phys. Condens. Matter 24, 456004 (2012).

44. Zhang, F. C. \& Rice, T. M. Effective Hamiltonian for the superconducting $\mathrm{Cu}$ oxides. Phys. Rev. B 37, 3759-3761 (1988).

45. Kitaoka, Y. et al. Orbital frustration and resonating valence bond state in the spin-1/2 triangular lattice $\mathrm{LiNiO}_{2}$. J. Phys. Soc. Jpn. 67, 3703-3706 (1998)

46. Korotin, M. A., Anisimov, V. I., Khomskii, D. I. \& Sawatzky, G. A. $\mathrm{CrO}_{2}$ : A self doped double exchange ferromagnet. Phys. Rev. Lett. 80, 4305-4308 (1998).

47. Chen, Z., Li, J. \& Zeng, X. C. Unraveling oxygen evolution in Li-rich oxides: a unified modeling of the intermediate peroxo/superoxo-like dimers. J. Am. Chem. Soc. 141, 10751-10759 (2019).

48. Yahia, M. B., Vergnet, J., Saubanère, M. \& Doublet, M. L. Unified picture of anionic redox in Li/Na-ion batteries. Nat. Mater. 18, 496-502 (2019).

49. Chen, H. \& Islam, M. S. Lithium extraction mechanism in Li-rich $\mathrm{Li}_{2} \mathrm{MnO}_{3}$ involving oxygen hole formation and dimerization. Chem. Mater. 28, 6656-6663 (2016).

50. Mortemard de Boisse, B., Jang, J., Okubo, M. \& Yamada, A. Cobalt-free O2type lithium-rich layered oxides. J. Electrochem. Soc. 165, A3630-A3633 (2018).

51. R. A. House, et al. First-cycle voltage hysteresis in Li-rich $3 d$ cathodes associated with molecular $\mathrm{O}_{2}$ trapped in the bulk. Nat. Energy (2020) https:// doi.org/10.1038/s41560-020-00697-2.

52. Song, B. et al. A novel P3-type $\mathrm{Na}_{2 / 3} \mathrm{Mg}_{1 / 3} \mathrm{Mn}_{2 / 3} \mathrm{O}_{2}$ as high capacity sodiumion cathode using reversible oxygen redox. J. Mater. Chem. A 7, 1491-1498 (2019). 
53. Kresse, G. \& Furthmüller, J. Efficient iterative schemes for ab initio total-energy calculations using a plane-wave basis set. Phys. Rev. B 54, 11169-11186 (1996).

54. Kresse, G. \& Furthmüller, J. Efficiency of ab-initio total energy calculations for metals and semiconductors using a plane-wave basis set. Comput. Mater. Sci. 6, 15-50 (1996).

55. Blöchl, P. E. Projector augmented-wave method. Phys. Rev. B 50, 17953-17979 (1994).

56. Perdew, J. P., Burke, K. \& Ernzerhof, M. Generalized gradient approximation made simple. Phys. Rev. Lett. 77, 3865-3868 (1996).

57. Perdew, J. P., Burke, K. \& Ernzerhof, M. Generalized gradient approximation made simple. Phys. Rev. Lett. 78, 1396 (1997). [Phys. Rev. Lett. 77, 3865 (1996)].

58. Dudarev, S. L., Botton, G. A., Savrasov, S. Y., Humphreys, C. J. \& Sutton, A. P. Electron-energy-loss spectra and the structural stability of nickel oxide: an LSDA+U study. Phys. Rev. B 57, 1505-1509 (1998).

59. Jain, A. et al. Formation enthalpies by mixing GGA and GGA+U calculations. Phys. Rev. B 84, 045115 (2011).

60. Grimme, S., Antony, J., Ehrlich, S. \& Krieg, H. A consistent and accurate ab initio parametrization of density functional dispersion correction (DFT-D) for the 94 elements H-Pu. J. Chem. Phys. 132, 154104 (2010).

61. Momma, K. \& Izumi, F. VESTA 3 for three-dimensional visualization of crystal, volumetric and morphology data. J. Appl. Crystallogr. 44, 1272-1276 (2011).

62. Okhotnikov, K., Charpentier, T. \& Cadars, S. Supercell program: a combinatorial structure-generation approach for the local-level modeling of atomic substitutions and partial occupancies in crystals. J. Cheminf. 8, 17 (2016).

63. Urban, A., Seo, D.-H. \& Ceder, G. Computational understanding of Li-ion batteries. npj Comput. Mater. 2, 16002 (2016).

\section{Acknowledgements}

This work was financially supported by the Ministry of Education, Culture, Sports, Science and Technology (MEXT), Japan; Grant-in-Aid for Specially Promoted Research No. 15H05701 and Grant-in-Aid for Scientific Research (S) No. 20H05673. This work was also supported by "Elements Strategy Initiative for Catalysts and Batteries (ESICB)". M. O. was financially supported by JSPS KAKENHI (Grant Number 19H05816, 18K19124, and 18H03924), and the Asahi Glass Foundation. X-ray absorption/emission spectroscopy at BL07LSU of SPring- 8 was performed by joint research in SRRO and ISSP, the University of Tokyo (Proposal No. 2020A7474, 2019B7456, 2019A7452, 2018B7590, and 2018A7560).

The authors are grateful to J. Miyawaki and Y. Harada at the University of Tokyo for their support on the X-ray absorption/emission experiments.

\section{Author contributions}

M.O. and A.Y. conceived and directed the project. A.T. and B.M.B. synthesized and characterized $\mathrm{Na}_{2} \mathrm{Mn}_{3} \mathrm{O}_{7}$. X.M.S. conducted theoretical calculations. J.K. measured SAED patterns. A.T., K.K., and D.A. conducted synchrotron X-ray absorption/emission spectroscopy. All authors wrote the manuscript.

\section{Competing interests}

The authors declare no competing interests.

\section{Additional information}

Supplementary information is available for this paper at https://doi.org/10.1038/s41467020-20643-w.

Correspondence and requests for materials should be addressed to A.Y.

Peer review information Nature Communications thanks Naoaki Yabuuchi, and the other, anonymous, reviewer(s) for their contribution to the peer review of this work. Peer reviewer reports are available.

Reprints and permission information is available at http://www.nature.com/reprints

Publisher's note Springer Nature remains neutral with regard to jurisdictional claims in published maps and institutional affiliations.

(c) (i) Open Access This article is licensed under a Creative Commons Attribution 4.0 International License, which permits use, sharing, adaptation, distribution and reproduction in any medium or format, as long as you give appropriate credit to the original author(s) and the source, provide a link to the Creative Commons license, and indicate if changes were made. The images or other third party material in this article are included in the article's Creative Commons license, unless indicated otherwise in a credit line to the material. If material is not included in the article's Creative Commons license and your intended use is not permitted by statutory regulation or exceeds the permitted use, you will need to obtain permission directly from the copyright holder. To view a copy of this license, visit http://creativecommons.org/ licenses/by/4.0\%

(C) The Author(s) 2021 